\title{
Hour Times Gram Per Milliliter Per Milligram Per Kilogram Per Day
}

National Cancer Institute

\section{Source}

National Cancer Institute. Hour Times Gram Per Milliliter Per Milligram Per Kilogram Per Day. NCl Thesaurus. Code C105465.

A dose calculation unit expressed in hours times grams per milliliter, divided by milligram per kilogram per day. 